\section{R. Krishnan Joins Editorial Board of MRS BULLETIN}

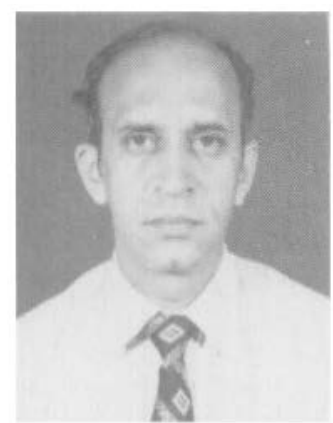

Dr. Rangachari Krishnan, director of the Naval Chemical and Metallurgical Laboratory, Naval Dockyard, Bombay, India, has joined the Editorial Board of the MRS BULLETIN. Krishnan will bring expanded international expertise to the position.

Krishnan received his MA and MSc from Madras University, and his PhD from Bombay University. He is a member of the Indian Institute of Metals, the Indian Physics Association, and the Indian Vacuum Society. A recipient of the National Metallurgists Day Award of the Ministry of Steel and Mines, he was also elected a Fellow of both the Indian Academy of Sciences and the Indian National Science Academy.

Krishnan is editor of Transactions of the Indian Institute of Metals and a member of the Editorial Board of Materials Science Forum. His publications include over 100 papers in international and Indian journals in the areas of physical metallurgy and materials science, with special emphasis on phase transformations and structureproperty correlations. His current research interests are the structure-property correlations in steels, titanium alloys, corrosion of marine engineering materials, and engineering and piezoelectric ceramics.

\section{Third Issue of 1987 Journal of Materials Research in Production}

The May/June 1987 issue (Vol. 2, No. 3) of Journal of Materials Research, expected to be published within six weeks, will include a lengthy review entitled "Crystal Chemical Incorporation of High Level Waste Species in Aluminotitanate Based Ceramics: Valence, Location, Radiation Damage and Hydrothermal Durability" by P.E. Fielding and T.J. White. This 32-page article is the very first comprehensive and expert review on the crystal chemistry of this specific area of nuclear waste management.

The following is a partial list of papers expected to appear in this issue:

- Crack Resistance by Interfacial Bridging: Its Role in Determining Strength Characteristics, by Robert F. Cook, Carolyn J. Fairbanks, Brian R. Lawn, and Yiu-Wing Mai

- Estimation of the IR Absorption of $\mathrm{ZnCl}_{2-}$ $\mathrm{KBr}$ Glass by Molecular Dynamics, by Satoru Inoue, Mitsuru Tamaki, Hiroshi Kawazoe, and Masayuki Yamane

- Four-Mode Behavior in $\operatorname{In}_{1-x} \mathrm{Ga}_{x} \mathrm{As}_{\mathrm{s}} \mathrm{P}_{1-y}$ Quaternary Alloy, by H.C. Gupta, Geeta
Sood, Jaishree Malhotra, Vijay Baboo Gupta, and B.B. Tripathi

- Hydrogen Concentration Gradients in Cathodically Charged Austenitic Stainless Steel, by D.G. Ulmer and C.J. Altstetter

- Intercalation of $\mathrm{MF}_{6}-$ Ions $(\mathrm{M}=\mathrm{Nb}$, Ta, As and $\mathrm{Sb}$ ) into HOPG using $\mathrm{Hg}^{2+}$ and $\mathrm{Hg}_{2}{ }^{2+}$ Salts, by P.K. Ummat, H. Zaleski, and W.R. Datars

- Ion-Beam Induced Formation of a Stable Phase at the Expense of an Otherwise Dominant Metastable Phase, by E.H. Lee and L.K. Mansur

- Kinetic Decomposition of $\mathrm{Ni}_{2} \mathrm{SiO}_{4}$ in Oxygen Potential Gradients, by K.T. Jacob and A.K. Shukla

- Single Crystal X-Ray Diffraction from an Icosahedral Quasi-Crystal, by A.R. Kortan, H.S. Chen, and J.V. Waszczak

- Thin Film Alloys of $B_{1} i_{1-x} S b_{x}$ Produced by Ion Beam Mixing and Their Thermoelectric Properties, by A.M. Ibrahim, D.A. Thompson and J.A. Davies

For information on article submission for Journal of Materials Research, contact Linda Krysinski, Editorial Office Supervisor, Journal of Materials Research, Materials Research Society, 9800 McKnight Road, Suite 327, Pittsburgh, PA 15237; telephone (412) 367-9111.

To subscribe to Journal of Materinls Research, contact Marketing Services, American Institute of Physics, 335 East 45th Street, New York, NY 10017; telephone (212) 661-9404.

\section{Obituaries}

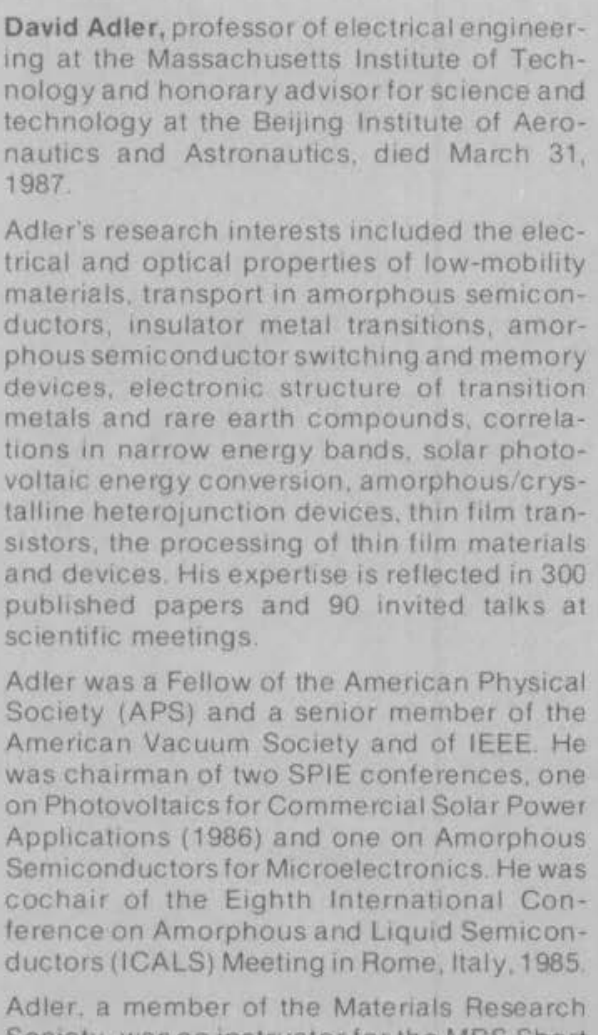

Course on Amorphous Semiconductor Materials and Devices. He also served as for two MRS symposia on Materials Issues in Applications of Amorphous Silicon Tech
nology at the 1985 and 1986 MRS Spring Meetings: American Physical Society (APS), died of director of Brookhaven National Laboratory rom 1973 through 1981, when he resigned as director to return to full-time research as a
senior physicist. His research spanned microtheory of scattering, radiation damage and rate processes in solids, and the uses of Vineyard served on numerous ad visory com mittees for the National Science Foundation, emy of Sciences. American Physical Society,
and several universities. He was a member of the Materials Research Council of DARPA since 1967 , and was chairman of the council's
He was chairman of the APS Division of Solid
He State Physics (1972-73), chairman of the APS
I Physical Review Letters. Vineyard was a Fellow of the Polytechnic Institute of New
York. American Academy of Arts and Sciences, AAAS, and APS. He was a member of John E. Hilliard, protessor of materials science and engineering at Northwestern ceived his BEng and PhD, both in metallurgy named Walter P. Murphy Professor at Northwestern in 1971.
Hilliard's research interests spanned diffusion, thermodynamics, phase transforma dal decomposition. He was co-editor of the
book Local Atomic Arrangements Studied by $X$-Ray Diffraction (Gordon and Breach, New York, 1966) and author or co-author of more
than 100 papers. Several of his most recent papers dealt with superconductivity, includAnti-Localization and Interaction Effects in $\mathrm{Nb}_{0.53} \mathrm{Ti}_{0.4}$ - Ge Multilayers," Solid State and J.B. Ketterson.

Hilliard was a member of The Metallurgical 1975-79). Since 1983 he was editor and Interfaces, Superlattices, and Thin Films at chairman of the Divisional Associate. Editors the 1986 MRS Fall Meeting in Boston. MA 